\title{
Innervation of the rat pineal gland by nerve fibres originating in the sphenopalatine, otic and trigeminal ganglia. A retrograde in vivo neuronal tracing study
}

\author{
Morten Møller*, Wei Liu \\ Institute of Medical Anatomy, Panum Institute, University of Copenhagen, \\ Blegdamsvej 3, DK-2200 Copenhagen, Denmark
}

(Received 19 January 1999; accepted 19 March 1999)

\begin{abstract}
The innervation of the rat pineal gland from the sphenopalatine, otic, superior cervical and trigeminal ganglia was investigated in animals by use of in vivo retrograde tracings. A solution of $2 \%$ Fluorogold was iontophoretically injected into the superficial pineal gland in a series of Wistar rats. After a survival time of 4-10 days, the animals were fixed by perfusion and the brains, sphenopalatine, otic, superior cervical and trigeminal ganglia were investigated with a fluorescence microscope. Many retrogradely labelled perikarya were found in the superior cervical ganglia, but a smaller number of neurones were also labelled in the sphenopalatine, otic and trigeminal ganglia. Injections of the tracer into the subarachnoidal space were used as the control for unspecific uptake and transport of the tracer. The input to the pineal gland from the parasympathetic sphenopalatine and otic ganglia might be involved in the regulation of the annual rhythms of the pineal gland. The projections from the sensory trigeminal ganglion could be involved in the control of the blood flow of the gland. (C) Inra/Elsevier, Paris.
\end{abstract}

\section{pineal innervation / Fluorogold / sphenopalatine / otic / trigeminal ganglion}

Résumé - Innervation de la glande pinéale de rat par des fibres nerveuses provenant des ganglions sphénopalatin, otique et trijumeau. Une étude par traçage rétrograde in vivo. L'innervation de la glande pinéale de rat à partir des ganglions sphénopalatin, otique, cervical supérieur et trijumeau a été étudiée chez des animaux par traçage rétrograde in vivo. Une solution de Fluorogold $(2 \%)$ a été injectée par iontophorèse dans la glande pinéale superficielle de rats Wistar. Après un temps de survie de 4 à $10 \mathrm{j}$, les animaux ont été fixés par perfusion et les cerveaux et les ganglions sphénopalatin, otique, cervical supérieur et trijumeau ont été analysés au microscope à fluorescence. De nombreux perikaryons marqués de manière rétrograde ont été trouvés dans les ganglions cervicaux supérieurs, mais un nombre plus faible de neurones ont aussi été marqués dans les ganglions sphénopalatin, otique et trijumeaux. Des injections du traceur dans l'espace subarachnoïdien ont été utilisées comme témoin pour une capture et un transport non spécifique du traceur. Les afférences vers

\footnotetext{
* Correspondence and reprints

E-mail: morten.m@mai.ku.dk
} 
la glande pinéale à partir des ganglions parasympathiques, sphénopalatin et otique pourraient être impliquées dans la régulation des rythmes annuels de la glande pinéale. Les projections à partir du ganglion sensoriel trijumeau pourraient être impliquées dans le contrôle du débit sanguin de la glande. (C) Inra/Elsevier, Paris.

\section{innervation de la pinéale / Fluorogold / sphénopalatin / otique / ganglion trijumeau}

\section{INTRODUCTION}

Anatomical studies have shown that the mammalian pineal gland is innervated by nerve fibres originating from the perikarya in the brain (for a review, see [15]) and by nerve fibres originating from the perikarya located in the peripheral ganglia (for review, see [17]).

The peripheral pineal innervation from the superior cervical ganglion [4] has been documented in all investigated species and shown to be of functional importance for pineal physiology in many mammals [6]. However, strong anatomical evidence for the innervation of the pineal from parasympathetic ganglia has also been provided. Kenny [5] carried out a model study in this field on the monkey. After cutting the greater petrosal nerve, he observed a degeneration of nerve fibres in the pineal gland. The greater petrosal nerve provides the sphenopalatine ganglion with preganglionic parasympathetic nerve fibres. Therefore, the degenerating nerve fibres in the pineal gland, observed after cutting of the greater petrosal nerve, are probably degenerating second order neurones in the parasympathetic nervous system.

Immunohistochemical studies of neuropeptidergic fibres in the mammalian pineal have also pointed towards the sphenopalatine ganglion as the origin of pinealopetal nerve fibres [19]. Thus, both the vasoactive intestinal peptide (VIP) $[1,16]$ and peptide histidine isoleucine (PHI) [13] are present in intrapineal nerve fibres. These neuropeptides are abundant in cell bodies of the sphenopalatine ganglion [22] but not present in the perikarya of the superior cervical ganglion. The hypothesis that the VIP/ PHIergic intrapineal nerve fibres originated from the perikarya in the sphenopalatine ganglion has been further supported by retrograde tracings from the pineal gland of the Mongolian gerbil [27] and rat [7] which resulted in the labelling of the perikarya in the sphenopalatine ganglion. In the gerbil, combined tracing and immunohistochemistry further showed [27] that some of the labelled perikarya in the sphenopalatine ganglion also contained VIP.

Other parasympathetic ganglia than the sphenopalatine ganglion also have to be considered with regards pineal innervation. Thus, the otic ganglion contains many VIPergic perikarya and is known to innervate brain vasculature $[31,33]$. Whether this ganglion projects to the pineal gland is at the moment unknown.

Finally, the presence of a plexus of nerve fibres in the pineal gland containing substance $\mathrm{P}$ (SP) and the calcitonin gene-related peptide (CGRP) $[18,25,27]$ in the pineal gland of several mammalian species is responsible for raising questions on the origin of these peptidergic nerve fibres. In the gerbil, combined tracing with immunohistochemistry has indicated that the SPergic nerve fibres originate in the perikarya located in the trigeminal ganglion [27].

Criticism has been raised against the retrograde tracing studies. Thus, spreading of the tracer to meninges might result in false labelling of cell bodies after an unspecific uptake of the tracer into nerve fibres located in the pial membrane. We have therefore reinvestigated the innervation of the rat pineal gland by using Fluorogold as a retro- 
grade tracer. Fluorogold is taken up by damaged nerve fibres and not by intact nerve fibres. Thus, an unspecific uptake by meningeal fibres is not seen with this tracer. Our study shows that the injection of Fluorogold into the rat pineal gland results in labelling of perikarya in the parasympathetic sphenopalatine ganglion and otic ganglion, as well as in the sensory trigeminal ganglion.

\section{MATERIALS AND METHODS}

\subsection{Animals}

Twenty adult male Wistar rats, weighing $250-300 \mathrm{~g}$, were used in this investigation. The animals were kept in a 12:12 h light/darkness schedule (light on at 06:00) with food and water ad libitum. All animals were obtained from the animal department of the Panum Institute, Copenhagen, Denmark. The principles of laboratory animal care and specific national laws were followed.

\subsection{Injection of tracer and cryostat sectioning}

After tribromethanol anaesthesia i.p. ( $250 \mathrm{mg} \cdot \mathrm{kg}^{-1}$ animal), the animals were fixed in a Kopf stereotaxic apparatus. After a midline incision of the skin of the skull, the calvarium was exposed. Using a dental drill and fine metal needles, a trepanation of the skull was made above the confluens sinuum. A pulled glass microelectrode with a tip diameter of $25-50 \mu \mathrm{m}$ was filled with a solution of Fluorogold $(2 \%$ Fluorogold in $0.1 \mathrm{M}$ acetate buffer, $\mathrm{pH} 3.3$ ) and, after lowering the electrode into the pineal gland through the confluens sinuum, the tracer was injected iontophoretically by using a positive current of $10 \mu \mathrm{A}$ ( $7 \mathrm{~s}$ on; $7 \mathrm{~s}$ off) for $15 \mathrm{~min}$. After removal of the glass electrode the skin was sutured and the animals were allowed to survive for 4-10 days before fixation.

Eight animals, injected with the Fluorogold tracer directly into the subarachnoidal space surrounding the superficial pineal gland, served as controls.

\subsection{Perfusion fixation}

The animals were re-anaesthetized with tribromethanol as described above and perfused through the heart with ice-cold heparinized $\left(15000 \mathrm{IU} \cdot \mathrm{L}^{-1}\right)$ phosphate-buffered saline $(\mathrm{pH}$ 7.4 , PBS) for 2 min followed by $4 \%$ paraformaldehyde in $0.1 \mathrm{M}$ sodium phosphate buffer (pH 7.2) for $10 \mathrm{~min}$. The brains, the sphenopalatine ganglia, the otic ganglia, the superior cervical ganglia and the trigeminal ganglia were removed and postfixed in the same fixative for 2 days and transferred to PBS. The brains were then cryoprotected for 2 days in $20 \%$ sucrose, frozen in crushed dry ice, sectioned in a cryostat at a thickness of $15 \mu \mathrm{m}$ and collected on gelatinized glass slides.

\subsection{Fluorescence microscopy}

The sections were viewed in a Zeiss Axiophot equipped with epifluorescence and Zeiss interference filters (excitation filter G365, mirror LP420 and barrier filter LP430), and photographed on Kodak ektachrome 320T film for colour slides or Tri-X 400 film for black and white prints.

\section{RESULTS}

\subsection{Location and morphology of the investigated ganglia}

The sphenopalatine ganglion lies between the medial surface of the maxillary nerve (figure 1) and the nasal orbital wall (figure 2) in the pterygopalatine fossa. The ganglion is elongated in the rostro-caudal direction endowed with two or three swellings along its length. Caudally, the ganglion is connected with the nerve of the pterygoid canal (Vidian nerve) and rostrally the pterygopalatine nerve (figure 2) extends from the ganglion together with the orbital branches of the ganglion. More caudally, the palatine branch leaves the ganglion to enter the major palatine canal (figure 2). Several delicate branches leave the ganglion in the dorsal direction located on the medial wall of the orbit to enter the anterior ethmoidal foramen together with the nasociliary nerve (figure 2). These branches enter the cranial cavity to supply the blood vessels of the brain. 


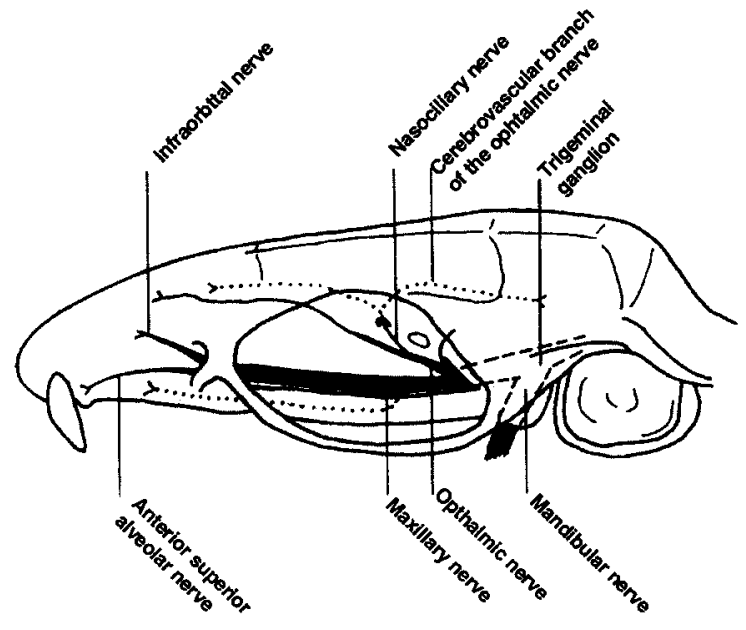

Figure 1. Lateral view of the skull of the rat showing the location of the trigeminal nerve and the branches of the trigeminal nerve.
The otic ganglion exhibits a triangular shape from which a small nerve fibre emerges from one of the poles. The ganglion is located close to the foramen ovale beneath the sphenoid bone (figure 2). The ganglion is separated on its lateral surface from the maxillary nerve by the pterygopalatine artery, and connected to the lesser petrosal nerve, which in the rat is a branch from the greater petrosal nerve. The lesser petrosal nerve emerges from the skull through the petrotympanic fissure. Branches from the ganglion reach the mandibular and auriculotemporal nerves. The sympathetic fibres approach the ganglion via nerve fibres surrounding the pterygopalatine artery.

The large trigeminal ganglion is located in the middle cranial fossa (figure 1). The ganglion divides rostrally into the opthalmic, maxillary and mandibular nerves. The opthalmic and maxillary nerves enter the

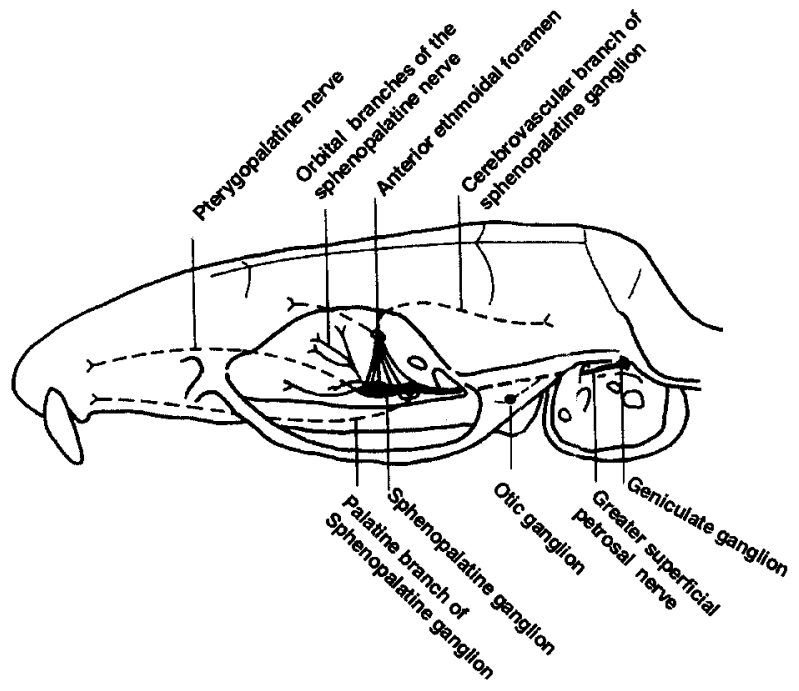

Figure 2. Lateral view of the skull of the rat showing the location of the spenopalatine and otic ganglia. 
orbit through the anterior lacerated foramen (foramen orbitorotundum) which corresponds to the foramen rotundum and superior orbital fissure in man. The opthalmic nerve gives rise to the nasociliary nerve which, through the ethmoidal foramen, innervates blood vessels in the anterior part of the brain.

The superior cervical ganglion is an elongated structure located on the neck just medial to the carotid bifurcation. The ganglion is easily recognized owing to the two slender nerves emerging from the rostral and caudal part of the ganglion.

\subsection{Retrograde tracings}

The fluorogold injections into the superficial pineal gland were for the most part very small but the size depended on the length of the injection time. A large injection, approximately $100 \times 100 \mu \mathrm{m}$, is seen in figure 3. Several of the injections were smaller. The larger injections resulted in a more retrogradely labelled perikarya in the investigated ganglia.

After injections of Fluorogold into the pineal gland (figure 3), labelled perikarya were found in all three investigated ganglia on both the right and left side. The highest number of labelled perikarya, between 10 and 20 , was seen in the superior cervical ganglion (figure 4). The neurones were mostly located in the rostral part of the ganglion with fibres extending toward the rostral part of the ganglion.

Few neurones were observed in the sphenopalatine (figure 5), otic (figure 6) and trigeminal ganglia (figure 7) after the injection of Fluorogold into the superficial pineal gland. In the trigeminal and sphenopalatine ganglia two to four labelled neurones were observed. In the otic ganglion one to two neurones were labelled. However, the labelled perikarya were repeatedly observed after the large injections into the superficial pineal gland. In contrast, in cases where Fluorogold was injected into the subarachnoidal space, we rarely observed retrogradely labelled perikarya in the ganglia, and only after installation of large amounts of the tracer.

\section{DISCUSSION}

Our study confirms previous retrograde tracing studies in rodents showing perikarya located in the sphenopalatine [27] and trigeminal ganglia $[25,27]$ projecting to the pineal gland. In addition, this study further indicates that the otic ganglion also contains perikarya projecting to the pineal gland of the rat.

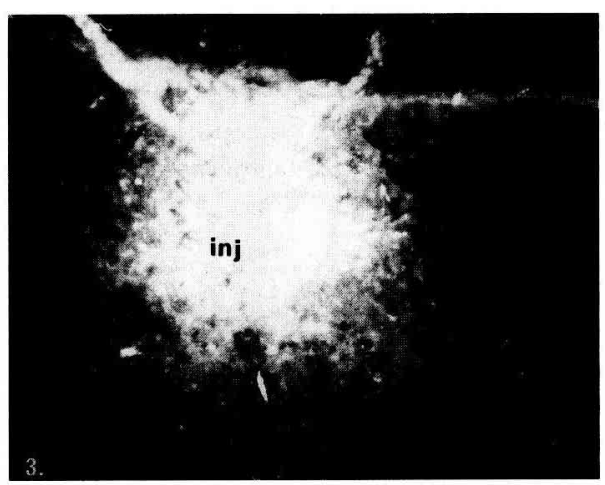

Figure 3. Sagittal section of part of the rat superficial pineal gland in which Fluorogold (inj) has been injected; original magnification $\times 50$.

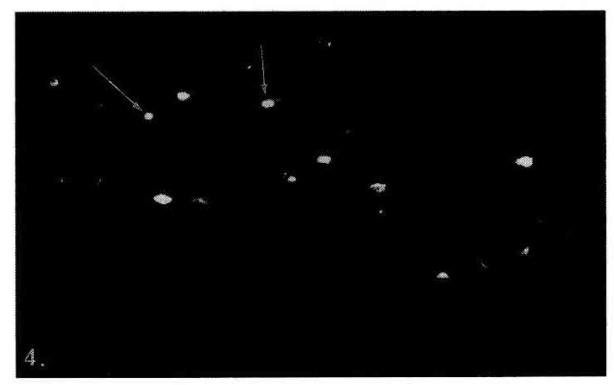

Figure 4. Retrogradely labelled perikarya (arrows) in the superior cervical ganglion of the rat after intrapineal injection of Fluorogold; original magnification $\times 110$. 

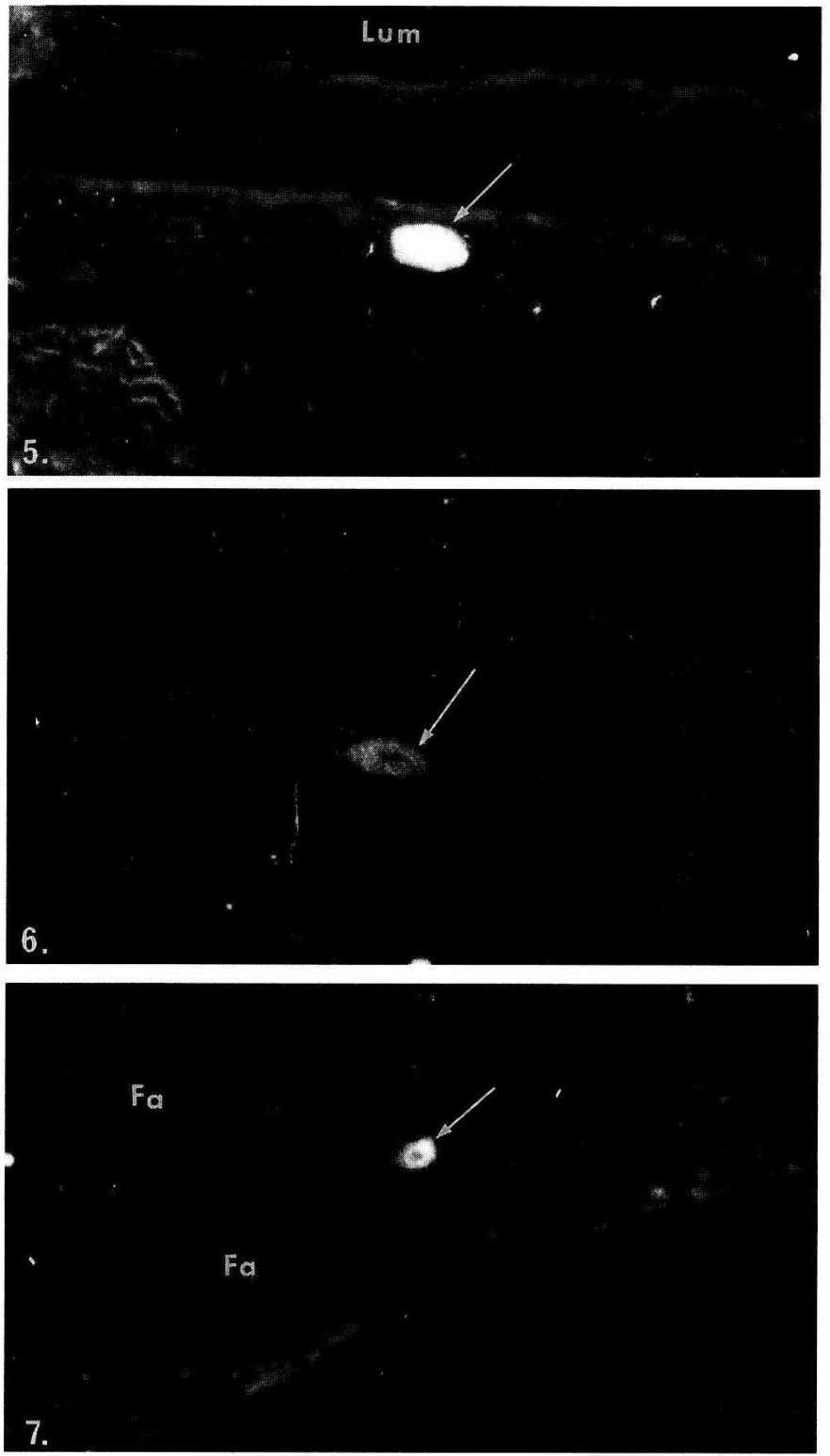

Figure 5. Retrogradely labelled perikaryon (arrow) in the sphenopalatine ganglion of the rat after intrapineal injection of Fluorogold. Lum = lumen in the accompanying blood vessel of the ganglion; original magnification $\times 250$.

Figure 6. Retrogradely labelled perikaryon (arrow) in the otic ganglion of the rat after intrapineal injection of Fluorogold; original magnification $\times 250$.

Figure 7. Retrogradely labelled perikaryon (arrow) in the trigeminal ganglion of the rat after intrapineal injection of Fluorogold. Nerve fascicles of the ganglion are seen between the perikarya. Fa $=$ nerve fibres fascicles; original magnification $\times 110$. 
A major pitfall with regards neuroanatomical retrograde tracings from the pineal gland is the unspecific labelling of the perikarya innervating the meninges surrounding the gland. Some tracers, used in earlier studies, are easily taken up by nerve fibres and the risk of unspecific transport of the tracer is high. In contrast, Fluorogold is mostly taken up by damaged nerve fibres, and in this study even major injections of the tracer into the subarachnoidal space only rarely labelled perikarya in the investigated ganglia.

Our finding of neurones in the sphenopalatine ganglion and in the otic ganglion projecting to the pineal gland is not surprising. All three ganglia are known to contain perikarya innervating the arteries of the brain [30-33]. The blood vessels of the pineal gland are derived from the blood vessels in the pineal capsule which is a part of the pial meningeal membrane. Therefore, it is logical that the same ganglia also innervate the blood vessels inside the pineal gland.

Combined retrograde tracings and transmitter immunohistochemistry in the gerbil have shown VIP-containing neurones in the sphenopalatine ganglion innervating the pineal gland [27]. However, several immunohistochemical studies show that nerve fibres containing VIP leave the perivascular spaces and enter the pineal parenchyma. Therefore, these nerve fibres might influence the hormone synthesis of the pinealocytes. Receptors for VIP $[8,16]$ and PHI [34], sister peptides encoded from the same gene $[3,23]$ and located in neurones of the sphenopalatine ganglion, are present on the pinealocytes. Both peptides have been shown to stimulate melatonin synthesis in cultured pinealocytes [14, 28 $29,36]$.

Innervation of the pineal gland from the trigeminal ganglion is a new concept. This ganglion is the sensory ganglion of the 5 th cranial nerve. However, for several years the trigeminal ganglion has also been known to contain SPergic neurones projecting with sensory nerve endings to the brain vasculature. Substance P, released from these neurones, is able to dilate pial vessels $[12,35]$.

Substance $P$ has been found in intrapineal nerve fibres of several species $[10,11$, 18, 25-27]. However, to our knowledge, experiments up to now have failed to show any influence on melatonin secretion. Therefore, the SP-containing nerve fibres of the pineal might influence the blood flow of the pineal gland and not melatonin secretion.

Recently PACAP has also been shown in intrapineal nerve fibres [21]. This peptide stimulates melatonin synthesis [28, 29] and receptors are located on the cell membrane of the pinealocytes $[9,24]$. In the gerbil, combined retrograde tracings and immunohistochemistry have indicated that the perikarya of the PACAPergic nerve fibres are located in the trigeminal ganglion. In a recent study on the rat [21], we have demonstrated a nearly $100 \%$ colocalization of PACAP and CGRP, the latter present in numerous perikarya in the trigeminal ganglion [2].

The physiological importance of the nervous input from the non-sympathetic ganglia is still enigmatic. However, annual variations of the content of neuropeptides in the pineal have been demonstrated [20]. We have therefore suggested that these ganglia might be involved in the regulation of annual rhythms of the mammalian pineal. The functional importance of the nervous input from the trigeminal ganglion to the pineal gland is also unknown. It might represent an input to the blood vessels or might be the anatomical substrate for a sensory feedback reflex from the pineal to the brain stem.

\section{REFERENCES}

[1] Cozzi B., Mikkelsen J.D., Merati D., Capsoni S., Møller M., Vasoactive intestinal peptide-like immunoreactive nerve fibers in the pineal gland of the sheep, J. Pineal Res. 8 (1990) 41-47. 
[2] Edvinsson L., Mulder H., Goadsby P.J., Uddman R., Calcitonin gene-related peptide and nitric oxide in the trigeminal ganglion; cerebral vasodilatation from trigeminal nerve stimulation involves mainly calcitonin gene-related peptide, J. Auton. Nerv. Syst. 70 (1998) 15-22.

[3] Itoh N., Obata, K, Yanaihara Y., Okamoto H., Human preprovasoactive intestinal polypeptide contains a novel PHI-27-like peptide, PHM-27, Nature 304 (1983) 547-549.

[4] Kappers J.A., The development, topographical relations and innervation of the epiphysis cerebri in the albino rat, Z. Zellforsch. 52 (1960) 163-215.

[5] Kenny G.C.T., The 'nervus conarii' of the monkey. An experimental study, J. Neuropath. Exp. Neurol. 20 (1961) 563-570.

[6] Klein D.C., Regulation of pineal serotonin $N$-acetyltransferase activity, Biochem. Soc. Trans. 20 (1992) 299-304.

[7] Larsen P.J., Enquist L.W., Card P.J., Characterization of the multisynaptic neuronal control of the rat pineal gland using viral transneuronal tracing, Eur. J. Neurosci. 10 (1998) 128-145.

[8] Martin J.L., Dietl M.M., Hof P.R., Palacios J.M., Magistretti P.J., Autoradiographic mapping of mono ${ }^{125}$ iodo- $[\text { tyr }]^{10}$, $[\mathrm{Met}]^{17}$ vasoactive intestinal peptide binding sites in the rat brain, Neuroscience 23 (1987) 539-565.

[9] Masuo Y., Ohtaki T., Masuda Y., Tsuda M., Fujino M., Binding sites for pituitary adenylate cyclase activating polypeptide (PACAP): comparison with vasoactive intestinal polypeptide (VIP) binding site localization in rat brain sections, Brain Res. 575 (1992) 113-123

[10] Matsushima S., Sakai Y., Hira Y., Oomori Y., Daikoku S., Immunohistochemical studies on sympathetic and non-sympathetic nerve fibers and neuronal cell bodies in the pineal gland of cotton rats, Sigmodon hispidus, Arch. Histol. Cytol. 57 (1994) 47-58.

[11] Matsushima S., Sakai Y., Hira Y., Sprouting of non-sympathetic myelinated and unmyelinated fibres in response to chronic sympathetic denervation in the pineal gland of the Chinese hamster, J. Neurocyt. 24 (1995) 519-531.

[12] Mejia J.A., Pernow J., von Holst H., Rudehill A., Lundberg J.M., Effects of neuropeptide Y, calcitonin gene-related peptide, substance $P$, and capsaicin on cerebral arteries in man and animals, J. Neurosurgery 69 (1988) 913-918.

[13] Mikkelsen J.D., Møller M., Larsen P.J., Fahrenkrug, J., The presence of nerve fibers immunoreactive for vasoactive intestinal peptide (VIP), peptide histidine isoleucine (PHI), and preproVIP(111-122) in the mouse pineal gland, J. Pineal Res. 16 (1994) 50-56.

[14] Moujir F., Reiter R.J., Rodriguez C., Yaga K., $\beta$-adrenergic and peptide $N$-terminal histidine and $\mathrm{C}$-terminal isoleucine stimulation of $N$-acetyltransferase activity and melatonin pro- duction in the cultured rat pineal gland, Endocrinology 130 (1992) 2076-2082.

[15] Møller M., Fine structure of the pinealopetal innervation of the mammalian pineal gland, J. Microsci. Res. Technol. 21 (1992) 188-204.

[16] Møller M., Mikkelsen J.D., Fahrenkrug J., Korf H.W., The presence of vasoactive intestinal polypeptide (VIP)-like immunoreactive nerve fibres and VIP receptors in the pineal gland of the Mongolian gerbil (Meriones unguiculatus). An immunohistochemical and receptor autoradiographic study, Cell Tissue Res. 241 (1985) 333-340.

[17] Møller M., Ravault J.-P., Cozzi B., Zhang E., Phansuwan-Pujito P., Larsen P.J., Mikkelsen J.D., The multineuronal input to the mammalian pineal gland, Adv. Pineal Res. 6 (1991) 3-12.

[18] Møller M., Phansuwan-Pujito P., Govitrapong P., Schmidt P., Indications for a central innervation of the bovine pineal gland with substance P-immunoreactive nerve fibers, Brain Res. 611 (1993) 347-351.

[19] Møller M., Ravault J.-P., Cozzi B., The chemical neuroanatomy of the mammalian pineal gland: neuropeptides, Neurochem. Int. 28 (1996) 23-33.

[20] Møller M., Masson-Pévet M., Pévet P., Annual variations of the NPYergic innervation of the pineal gland of the European hamster (Cricetus cricetus): a quantitative immunohistochemical study, Cell Tissue Res. 291 (1998) 423-431.

[21] Møller M., Fahrenkrug J., Hannibal J., Innervation of the rat pineal gland by pituitary adenylate-cyclase activating polypeptide (PACAP)immunoreactive nerve fibres, Cell Tissue Res. (1999) in press.

[22] Nilsson C., Fahrenkrug J., Biosynthetic processing of preprovasoactive intestinal polypeptide in parasympathetic neurons of the sphenopalatine ganglion, J. Neurochem. 65 (1995) 2663-2670.

[23] Nishizawa M., Hayakawa Y., Yaniahara N, Okamoto, H., Nucleotide sequence divergence and functional constraint in VIP presursor mRNA evllution between human and rat, FEBS Lett. 183 (1987) 55-59.

[24] Olcese J., McArdle C., Mikkelsen J.D., Hannibal $\mathbf{J}$., PACAP and type I PACAP receptors in the pineal gland, Ann. N.Y. Acad. Sci. (USA) 805 (1996) 595-600.

[25] Reuss S., Riemann R., Vollrath L., Substance Pand calcitonin gene-related peptide-like immunoreactive neurons in the rat trigeminal ganglion - with special reference to meningeal and pineal innervation, Acta Histochem. 92 (1992) 104-109.

[26] Rønnekleiv O.K., Distribution in the macaque pineal of nerve fibers containing immunoreactive substance $P$, vasopressin, oxytocin, and neurophysins, J. Pineal Res. 5 (1988) 259-271. 
[27] Shiotani Y., Yamano M., Shiosaka S., Emson P.C., Hillyard C.J., Girgis S., MacIntyre I., Distribution and origins of substance $\mathrm{P}$ (SP)-, calcitonin gene-related peptide (CGRP)-, vasoactive intestinal polypeptide (VIP)- and neuropeptide $Y$ (NPY)-containing nerve fibers in the pineal gland of gerbils, Neurosci. Lett. 70 (1986) 187-192.

[28] Simonneaux V., Ouichou A., Pèvet P., Vasoactive intestinal peptide stimulates melatonin release from perifused pineal glands of rats, J. Neural Transm. 79 (1990) 69-79.

[29] Simonneaux V., Ouichou A., Pévet P., Pituitary adenylate cyclase-activating polypeptide (PACAP) stimulates melatonin synthesis from rat pineal gland, Brain Res. 603 (1993) 148-152.

[30] Suzuki N., Hardebo J.E., The pathway of parasympathetic nerve fibers to cerebral vessels from the otic ganglion in the rat, J. Auton. Nerv. Syst. 36 (1991) 39-46.

[31] Suzuki N., Hardebo J.-E., Owman Ch., Origins and pathways of cerebrovascular vasoactive intestinal polypeptide-positive nerves in the rat, J. Cereb, Blood Flow Metab. 8 (1988) 697-712.

[32] Suzuki N., Hardebo J.-E., Owman Ch., Trigeminal fibre collaterals storing substance $\mathbf{P}$ and $\mathrm{cal}$ - citonin gene-related peptide associate with the ganglion cells containing choline acetyltransferase and vasoactive intestinal polypeptide in the sphenopalatine ganglion of the rat. An axon reflex modulation parasympathetic ganglionic activity?, Neuroscience 30 (1989) 595-604.

[33] Suzuki N., Hardebo J.E., Owman C., Origins and pathways of choline acetyltransferase-positive parasympathetic nerve fibers to cerebral vessels in rat, J. Cereb. Blood Flow Metab. 10 (1990) 399-408.

[34] Tsuchiaya M., Kaku K., Matsuda M., Kaneko T., Yanaihara N., Demonstration of receptors specific for peptide $N$-terminal histidine and C-terminal isoleucine (PHI) using rat PHI and rat dispersed pineal cells, Biomed. Res. 8 (1987) 41-51.

[35] Wahl M., Local chemical, neural, and humoral regulation of cerebrovascular resistance vessels, J. Cardiovasc. Pharmacol. 7 (1985) (suppl. 3) 36-46.

[36] Yuwiler A., Vasoactive intestinal peptide stimulation of pineal serotonin- $N$-acetyltransferase activity: general characteristics, J. Neurochem. 41 (1987) 146-153. 